\title{
Alanine Measurement
}

National Cancer Institute

\section{Source}

National Cancer Institute. Alanine Measurement. NCI Thesaurus. Code C122091.

The determination of the amount of alanine present in a sample. 